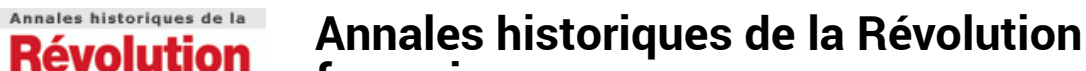

française française

352 | avril-juin 2008

Les temps composés de l'économie

\section{Éric J. Hobsbawm, Aux armes, historiens. Deux siècles d'histoire de la Révolution française}

\section{Claude Mazauric}

\section{Q OpenEdition}

1 Journals

Édition électronique

URL : https://journals.openedition.org/ahrf/11026

DOI : $10.4000 /$ ahrf. 11026

ISSN : 1952-403X

\section{Éditeur :}

Armand Colin, Société des études robespierristes

\section{Édition imprimée}

Date de publication : 1 juin 2008

Pagination : 285-287

ISBN : 978-2200-92514-7

ISSN : 0003-4436

\section{Référence électronique}

Claude Mazauric, «Éric J. Hobsbawm, Aux armes, historiens. Deux siècles d'histoire de la Révolution française », Annales historiques de la Révolution française [En ligne], 352 | avril-juin 2008, mis en ligne le 18 décembre 2009, consulté le 22 avril 2022. URL : http://journals.openedition.org/ahrf/11026 ; DOI : https://doi.org/10.4000/ahrf.11026

Ce document a été généré automatiquement le 22 avril 2022.

Tous droits réservés 


\title{
Éric J. Hobsbawm, Aux armes, historiens. Deux siècles d'histoire de la Révolution française
}

\author{
Claude Mazauric
}

\section{RÉFÉRENCE}

Éric J. Hobsbawm, Aux armes, historiens. Deux siècles d'histoire de la Révolution française, traduit de l'anglais par Julien Louvrier, Paris, La Découverte, 2007, 154 p., ISBN

978-2-7071-4982-4, 14,50€

Publié en 1990, voici enfin traduit en français, dix-sept ans plus tard - mieux vaut tard que jamais !-, le brillantissime et combatif essai d'Éric Hobsbawm: un ouvrage qui a contribué par son alacrité et sa largeur de vues, mieux que tout autre dans la sphère historiographique de langue anglaise, à mettre sur la défensive les adeptes, promoteurs et grands prêtres, de la vulgate anti-révolutionnaire qui a dominé l'espace public occidental et post-soviétique avant, pendant et après le bicentenaire de 1989. Transcription, sensiblement augmentée, nous dit l'auteur, de trois conférences prononcées à l'Université Rutgers à Brunswick (New Jersey) en avril 1989, la première édition de cet essai a paru en 1990 chez Verso (Londres et New York) sous le titre Echoes of The Marseillaise. Two Centuries on the French Revolution. Dans sa traduction française, le texte de l'essai se trouve complété d'une "post-face inédite» rédigée en 2007 par Hobsbawm, qui regarde avec un sage optimisme le fait que « la tentative pour éliminer l'élément social de toutes les analyses ou interprétations de la Révolution a dû être abandonnée" (p. 134). Voilà qui tranche avec les lamentations ordinaires qui paraissent ignorer le fait que le succès idéologico-médiatique dans l'espace public des points de vue hostiles à la Révolution, puis les vagues successives de canailleries antirobespierristes, n'ont en rien amoindri la fécondité de la recherche historique sur la période révolutionnaire, ni affaibli la portée et l'originalité des travaux qui en révèlent l'immense portée et la signification historique. Au-delà de nos modestes personnes, 
pour l'avenir du monde et de la civilisation, pour la philosophie, c'est cela seul qui importe. Le reste ressortit de la conjoncture courte.

2 «L'adrénaline nécessaire [sic] » à l'écriture de son essai, selon son dire, Éric Hobsbawm l'a puisée dans la lecture des «considérations françaises les plus récentes sur la Révolution ». Entendons simplement : tout ce qu'avait alors produit François Furet ou qui pouvait se rattacher à son magistère plus ou moins international. Mais, lecture faite, on mesurera aisément que c'est en raison de son immense culture d'historien et de son inépuisable fécondité de penseur non-conformiste, qu'Hobsbawm a pu mobiliser cette somme impressionnante d'arguments qui donnent toute leur force démonstrative aux quatre chapitres, correspondant à la recomposition des trois conférences prononcées à Rutgers, dont la succession forme la structure de son essai. Le premier chapitre, «Une révolution bourgeoise ", fonde une problématique attentive à marquer l'étendue et les limites d'une Révolution, dont le second chapitre («Dépasser la révolution bourgeoise ») aide à saisir l'importance historique et la force des dynamiques qui se sont greffées sur elle. Le troisième chapitre, "D'un centenaire à l'autre ", place en regard, non seulement la révolution bolchevique et la Révolution française, mais plus généralement conduit à observer le mouvement de l'histoire contemporaine sous l'éclairage des aspirations révolutionnaires pérennes auxquelles la Révolution française et ses relais au XIX ${ }^{\mathrm{e}}$ siècle ont donné un élan jamais démenti. C'est dans une note de ce chapitre que se trouve le rejet sans appel de l'article de François Furet paru dans le Dictionnaire critique, connu sous le titre « Histoire universitaire de la Révolution", article que "l'on peut considérer", écrit Hobsbawm, "comme un réquisitoire personnel fonctionnant par omission » (p. 148)! Le quatrième chapitre, "Survivre au révisionnisme ", est une vigoureuse riposte aux actuelles déformations, faux-procès, rodomontades et retours en arrière historiographiques de caractère purement idéologique, qu'on trouve toujours camouflés derrière de prétendues et hypocrites exigences de " renouvellement » méthodologique. La sèche énumération des développements successifs du livre de Hobsbawm ne dit cependant pas la richesse des analyses et la variété des références : révolution bourgeoise? Hobsbawm rappelle avec insistance que ce concept, qu'on dit « marxiste » est droit sorti des écrits des historiens libéraux de la Restauration (Guizot, Mignet, Thierry) et même de la Monarchie de Juillet (Tocqueville), d'ailleurs avec celui de lutte des classes, et page 20, il précise que "bürgerliche révolution ne se trouve pas plus d'une douzaine de fois dans les 38 volumes des Marx-Engels Werke»! Nécessité de la Révolution? «Comme beaucoup des idées reprises plus tard avec enthousiasme par les marxistes, cette notion de la nécessité de la révolution établie par extrapolation historique (ce que Charles de Rémusat appela plus tard la «conviction géométrique qu'il existe une loi des révolutions du monde moderne » était celle des libéraux français » (p. 33). Dans les développements consacrés à la « réfraction de la révolution dans le prisme de la politique contemporaine » (p. 81), Éric Hobsbawm balaie toute une histoire de l'Europe aux $\mathrm{XIX}^{\mathrm{e}}$ et $\mathrm{XX}^{\mathrm{e}}$ siècles, en particulier celle qui est relative à la Révolution russe, à ses suites et à la Seconde guerre mondiale, que sa connaissance, ses engagements personnels et sa pratique des langues autant que ses recherches, lui ont permis de maîtriser comme nul autre. Quand il évoque l'œuvre des historiens contemporains de la Révolution, il n'hésite pas à placer au premier rang celle de Georges Lefebvre à propos duquel il écrit que « le monument le plus impressionnant qu'on pouvait ériger à l'occasion du cent-cinquantième anniversaire de la Révolution en 1939 [fut] un petit livre simplement intitulé Quatrevingt-neuf» (p. 94). Enfin, prenant de haut l'hypothèse « révisionniste », Hobsbawm juge 
(p. 123) que «le paradoxe du révisionnisme est qu'il cherche à diminuer la portée historique et la capacité de transformation d'une révolution, dont, à moins de cultiver un certain intellectualisme provincial ou de souffrir de cette myopie monographique qui est la maladie professionnelle la plus répandue chez les chercheurs fréquentant les archives, l'impact extraordinaire et durable est absolument évident ». Ajoutera-t-on qu'on voit mal, si la Révolution n'était que cet épisode superfétatoire d'une longue histoire obscure, pourquoi on se dresserait inlassablement, et encore une nouvelle fois en 2008, pour en dénoncer aussi bien les prétendues horreurs que les ambitions ? Enfin, s'appuyant en particulier sur les dernières recherches de Lynn Hunt, Hobsbawm conclut son ajout de 2007, par cette double sentence : 1- «La Révolution française a créé la langue dans laquelle nous évoquons la politique contemporaine et les affaires publiques »; 2- «Peut-être est-il venu pour les Français de prêter à nouveau l'oreille aux échos universels de La Marseillaise et de les entendre aussi fortement qu'on les entend dans le reste du monde » (p. 136-137).

3 Les quelques citations ici rappelées ne disent pas toute la richesse d'un livre bref et dense dont chacun(e) devrait prendre une connaissance directe. Mais, assurément, tout jeune historien, toute jeune historienne, s'engageant dans la voie compliquée et apparemment si problématique de la recherche dans le champ de l'histoire de la Révolution française, devrait être invité(e) à commencer sa réflexion par la lecture attentive de l'essai d'Éric Hobsbawm. Non parce que s'y trouverait le vrai en toute chose - le dogmatisme est étranger à la manière de faire d'un historien plein d'humour et constamment inspiré par la tradition historiographique britannique ! - mais parce qu'il donne à chacun les moyens de jeter un regard critique, rétrospectif et prospectif, sur un champ historiographique international que nul mieux que lui n'a si bien dominé. Ajoutons enfin que la traduction française qu'on doit à Julien Louvrier - historien averti par son travail de recherche, de la densité des débats interprétatifs - se signale par son élégance et sa précision (on signalera cependant deux courtes bavures : page 71 , on lit « le 9 thermidor an IV » au lieu de «an II », et page 86, il fallait écrire le Syllabus et non le « Syllabe »!).

4 Nous aurons attendu dix-sept ans avant de pouvoir lire en français l'essai percutant d'Éric Hobsbawm dont la lecture en anglais nous avait déjà révélé l'acuité, dans les années du post-bicentenaire; déjà, il nous fallut attendre six ans avant qu'un éditeur belge, avec le concours du Monde diplomatique, repousse l'interdit jeté contre un précédent essai historique d'Hobsbawm, consacré à l'histoire du court $\mathrm{XX}^{\mathrm{e}}$ siècle : de quoi, Hobsbawm, le plus célèbre des historiens britanniques, est-il donc devenu coupable? On comprendra donc que ces manières subtiles d'évitement, heureusement déjouées, disent assez aux lecteurs des AHRF, l'urgence et l'importance de consacrer le temps qu'il faut à la lecture indispensable de cet essai clairvoyant, enfin disponible. 